\title{
Hubungan Perceived Organizational Support terhadap Kinerja Dokter di Rumah Sakit Kota Makassar
}

\section{The Relationship between Perceived Organizational Support and Doctor Performance at Makassar City Hospital}

\author{
Syahrir A.Pasinringi*, A. Amirah Shalihah, Nurmala Sari \\ Fakultas Kesehatan Masyarakat,Universitas Hasanuddin \\ ("syahrir65@yahoo.com)
}

\begin{abstract}
ABSTRAK
Dokter adalah salah satu tenaga professional yang memiliki peranan penting dalam pelayanan rumah sakit. Persepsi dokter terkait dukungan organisasi dapat menumbuhkan kepercayaan dan kinerja dokter terhadap rumah sakit. Penelitian ini bertujuan untuk menganalisis hubungan Perceived Organizational Support (POS) terhadap kinerja dokter di Rumah Sakit Umum Daerah Kelas B Kota Makassar. Jenis penelitian ini adalah observasional analitik dengan rancangan cross sectional. Total sampel dalam penelitian ini adalah 126 responden dipilih dengan teknik simple random sampling. Data dianalisis dengan menggunakan uji korelasi pearson. Hasil penelitian menunjukkan bahwa terdapat hubungan antara perceived organizational support terhadap kinerja dokter dengan nilai $p 0,010<0,05$. POS memiliki hubungan terhadap kinerja dokter sehingga rumah sakit perlu meningkatkan keterlibatan dokter dengan menciptakan lingkungan kerja yang supportif dan menyusun program inovasi untuk meningkatkan rasa kepercayaan dokter terhadap rumah sakit. Kata kunci : Perceived organizational support, kinerja dokter
\end{abstract}

\begin{abstract}
Doctor is one of professionals who have an important role in the hospital services. Perception of doctor related organizational support can build doctor's trust and performance in hospitals. This study aims to analyze the relationship of Perceived Organizational Support (POS) on doctor performance in Class B General Hospital of Makassar City. This research is an observational analytic study with cross sectional design. The total sample in this study was 126 respondents selected by simple random sampling technique. Data were analyzed using Pearson correlation test. The results showed that there was a relationship between perceived organizational support and doctor performance with a $p$ value of 0,010<0,05. POS has a relationship to the performance of doctors so hospitals need to increase the involvement of doctors by creating a supportive work environment and creating an innovation program to increase doctors' trust in the hospital.
\end{abstract} Keywords: Perceived organizational support, doctor's performance 


\section{PENDAHULUAN}

Rumah sakit merupakan institusi pelayanan kesehatan yang menyelenggarakan pelayanan kesehatan perorangan secara paripurna yaitu promotif, preventif, kuratif dan rehabilitative. ${ }^{1}$ Peran yang cukup komprehensif ini menjadikan rumah sakit sebagai salah satu organisasi yang kompleks, padat karya dan padat pakar. Pengelolaan rumah sakit membutuhkan tenaga professional dari berbagai disiplin ilmu yang bekerja sama agar terselenggaranya penyelenggaraan pelayanan kesehatan yang bermutu, efektif, efisien, dan sesuai kebutuhan pasien.

Dokter merupakan salah satu tenaga professional yang memiliki peranan penting dalam pelayanan rumah sakit. Peran dokter yang selalu berinteraksi langsung dengan pasien untuk memberikan pelayanan medis menjadikan pentingnya kontribusi dokter dalam efektivitas organisasi. ${ }^{2}$ Oleh karena itu, evaluasi kinerja dokter perlu dilakukan secara berkala untuk menjamin pelayanan yang berkualitas dan berkesinambungan.

Penilaian terhadap kinerja dokter dapat dilihat dari perspektif kompetensi dokter dan kinerja dokter sebagai bagian dari organisasi. ${ }^{2,3}$ Penilaian kompetensi dokter mencakup pengetahuan klinis dan keterampilan sesuai standar profesi sedangkan kinerja dokter sebagai bagian dari organisasi mencakup sikap dan perilaku yang mendukung lingkungan sosial dan psikologis suatu organisasi seperti menawarkan diri, membantu sejawat, bekerja sama, dan mengikuti aturan.

Pelaksanaan penilaian kinerja dokter di Indonesia secara khusus dibahas dalam Kompetensi dan Kewenangan Staf (KKS) pada Standar Nasional Akreditasi Rumah Sakit (SNARS) edisi 1 tahun 2018 tentang perlunya diadakan evaluasi staf medis terkait perilaku, pengembangan professional, dan kinerja klinis. Penilaian kinerja berdasarkan standar KKS ini lebih fokus mengevaluasi mutu praktik profesional berkelanjutan, etik, dan disiplin staf medis. ${ }^{4}$ Konteks kinerja dokter sebagai bagian dari organisasi, indikator terkait pelayanan dokter juga dibahas dalam Pedoman Penyusunan Standar Pelayanan Minimum di Rumah Sakit. ${ }^{5}$ Penilaian sesuai SPM terdapat 22 pelayanan yang dinilai, terdapat 7 indikator yang mengukur kinerja dokter yaitu waktu tanggap pelayanan dokter, memberi pelayanan sesuai ketentuan jam buka pe- layanan, waktu tunggu, jam visite dokter spesialistik, penulisan resep sesuai formularium, kelengkapan pengisian rekam medik 24 jam setelah pelayanan dan kelengkapan informed consent setelah mendapatkan informasi. ${ }^{5}$

Berdasarkan data SPM Rumah Sakit Umum Daerah (RSUD) kelas B di kota Makassar, pencapaian 7 indikator terkait kinerja dokter menunjukkan capaian $57.14 \%$ dari standar $100 \% .^{6,78} \mathrm{Hal}$ ini menggambarkan perlunya perhatian terhadap indikator capaian kinerja dokter sesuai standar minimum (100\%). Rethans dalam Sathiadas menjelaskan bahwa faktor yang mempengaruhi kinerja dokter dapat dilihat dari faktor individu dan faktor sistem. ${ }^{2}$ Kopelman menjelaskan lebih spesifik terkait faktor sistem bahwa selain faktor individu, faktor yang mempengaruhi kinerja dokter adalah aspek organisasi. ${ }^{9}$ Konsep ini mendukung temuan beberapa penelitian yang menyatakan bahwa salah satu faktor yang mempengaruhi kinerja adalah faktor Perceived Organizational Support (POS). ${ }^{10}$

POS merupakan perlakuan yang diterima pegawai dari organisasi kemudian ditangkap sebagai stimulus dan diinterpretasikan menjadi persepsi atas dukungan organisasi. Namun penelitian terkait POS pada tenaga medis masih cukup terbatas dan masih diposisikan sebagai variabel mediasi terhadap kinerja. ${ }^{11,12}$ Penelitian ini akan menganalisis lebih detail terkait persepsi POS dokter dan hubungan langsung variabel POS terhadap kinerja. Berdasarkan uraian di atas, maka tujuan penelitian ini adalah untuk menganalisis hubungan Perceived Organizational Support terhadap kinerja dokter di Rumah Sakit Umum Daerah (RSUD) kelas B kota Makassar.

\section{BAHAN DAN METODE}

Penelitian ini merupakan penelitian observasional analitik dengan rancangan cross sectional. Penelitian dilaksanakan di Rumah Sakit Umum Daerah Kelas B Kota Makassar yang terdiri dari RSUD Haji, RSUD Kota Makassar dan RSUD Labuang Baji pada bulan Maret hingga Desember 2018. Ketiga rumah sakit ini merupakan RSUD kelas B yang ada di kota Makassar. Populasi penelitian adalah seluruh dokter yang melakukan pelayanan dan bertugas di RSUD kelas B kota Makassar. Penentuan jumlah sampel menggunakan rumus Lameshow sehingga didapatkan 
total sampel dalam penelitian ini sebanyak 126 dokter. Adapun penentuan jumlah sampel pada setiap rumah sakit menggunakan rumus proporsional stratified random sampling.

Pengumpulan data dilakukan menggunakan kuesioner yang terdiri dari pertanyaan karakteristik demografi, Perceived Organizational Support (POS) dan kinerja dokter. Adapun POS yang dimaksud dalam penelitian ini adalah persepsi dokter tentang bagaimana organisasi menghargai kontribusi dan memberi perhatian terhadap kesejahteraan dokter. ${ }^{13}$ Sedangkan kinerja dokter adalah persepsi dokter terkait hasil kerja yang dicapai sesuai dengan tanggung jawab yang telah diberikan. Pengukuran dan pemberian skor pertanyaan menggunakan skala Likert. Uji validitas dan reliabilitas untuk seluruh item pertanyaan pada kuesioner telah dilakukan. Berdasarkan hasil uji validitas didapatkan bahwa setiap pertanyaan memiliki koefisiensi relasi $r \geq 0.3061$ atau lebih besar dari nilai $r$ tabel sehingga dinyatakan valid. Hasil uji reliabilitas diperoleh setiap pertanyaan memiliki koefisien Cronbach's Alpha $>0.60$ sehingga kuesioner reliable untuk digunakan. Analisis data pada penelitian ini menggunakan analisis univariat untuk mendeskripsikan karakteristik masing-masing variabel dan analisis bivariat dilakukan untuk mengetahui hubungan antara variabel independen Perceived Organizational Support (POS) terhadap variabel dependen yaitu kinerja dokter. Uji statistik yang digunakan adalah korelasi pearson. Data yang yang telah dianalisis disajikan dalam bentuk tabel dan narasi.

\section{HASIL}

Karakterstik demografi dalam penelitian ini meliputi umur, jenis kelamin, lama bekerja, pendidikan terakhir dan status kepegawaian. Tabel 1 menunjukkan bahwa dari 126 responden, 37 responden $(29,4 \%)$ berusia 46-55 tahun. Berdasarkan jenis kelamin, 74,6\% responden adalah perempuan. Sebagian besar responden telah bekerja dengan masa kerja di atas 10 tahun $(53,2 \%)$. Berdasarkan pendidikan terakhir dan status kepegawaian, $58,7 \%$ dari responden adalah dokter spesialis dan sebagian besar $(84,1 \%)$ responden adalah Pegawai Negeri Sipil (PNS).

Tingkat Perceived Organizational Support (POS) dan tingkat kinerja dokter pada tiap rumah
Tabel 1. Karakteristik Responden

\begin{tabular}{lcc}
\hline \multicolumn{1}{c}{ Karakteristik } & $\mathbf{n}$ & $\mathbf{\%}$ \\
\hline Usia & & \\
$26-35$ tahun & 33 & 26.2 \\
$36-45$ tahun & 30 & 23.8 \\
$46-55$ tahun & 37 & 29.4 \\
$56-65$ tahun & 26 & 20.6 \\
Jenis Kelamin & & \\
$\quad$ Laki-laki & 32 & 25.4 \\
$\quad$ Perempuan & 94 & 74.6 \\
Lama Bekerja & & \\
1 - 5 tahun & 35 & 27.8 \\
6- 10 tahun & 24 & 19.0 \\
> 10 tahun & 67 & 53.2 \\
Pendidikan Terakhir & & \\
dokter umum & 32 & 25.4 \\
drg. Umum & 13 & 10.3 \\
$\quad$ dr. spesialis & 74 & 58.7 \\
drg. Spesialis & 2 & 1.6 \\
dr. subspesialis & 2 & 1.6 \\
Magister & 1 & 0.8 \\
$\quad$ Doktoral & 2 & 1.6 \\
Status Kepegawaian & & \\
PNS & 106 & 84.1 \\
Lainya & 20 & 15.9 \\
\hline
\end{tabular}

Sumber : Data Primer, 2018

sakit, secara keseluruhan, $60 \%$ responden memiliki persepsi bahwa tidak ada dukungan dari organisasi. Ketiga rumah sakit, persepsi bahwa tidak adanya dukungan dari organisasi sebagian besar (70\%) pada responden di RSUD kota Makassar sedangkan persepsi bahwa adanya dukungan dari organisasi sebagian besar $(51,5 \%)$ pada responden di RSUD Haji. Berdasarkan persepsi kinerja dokter, diketahui bahwa tingkat kinerja dokter di RSUD Haji, RSUD Kota Makassar dan RSUD Labuang Baji hampir seluruhnya termasuk ke dalam kategori baik, hanya 7,5\% responden di RSUD Kota Makassar dengan tingkat kinerja dokter kurang baik. Responden di RSUD Haji dan RSUD Labuang Baji memiliki pesepsi baik terhadap kinerja sebesar 100\% (Tabel 2).

Adapun indikator dalam menilai tingkat Perceived Organizational Support (POS) pada penelitian ini dilihat berdasarkan indikator penghargaan organisasi terhadap kontribusi pegawai dan indikator perhatian organisasi terhadap kehidupan pegawai (Tabel 3). Persepsi responden organisasi terkait cara rumah sakit mengapresiasi usaha $(59,5 \%)$ dan menanggapi performa $(62,7 \%)$ 
Tabel 2. Distribusi Frekuensi Tingkat Perceived Organizational Support dan Kinerja Dokter Tiap Rumah Sakit

\begin{tabular}{lcccccccc}
\hline & \multicolumn{7}{c}{ Rumah Sakit } \\
\cline { 2 - 9 } \multicolumn{1}{c}{ Variabel } & RSUD Haji & $\begin{array}{c}\text { RSUD Kota } \\
\text { Makassar }\end{array}$ & $\begin{array}{c}\text { RSUD } \\
\text { Labuang Baji }\end{array}$ & Total \\
\cline { 2 - 9 } & $\mathbf{n}$ & $\mathbf{\%}$ & $\mathbf{n}$ & $\mathbf{\%}$ & $\mathbf{n}$ & $\mathbf{\%}$ & $\mathbf{n}$ & $\mathbf{\%}$ \\
\hline POS & 16 & 48,5 & 28 & 70 & 32 & 60,4 & 76 & 60,3 \\
$\quad \begin{array}{l}\text { Tidak Mendukung } \\
\quad \begin{array}{l}\text { Mendukung } \\
\text { Kinerja Dokter }\end{array}\end{array}$ & 17 & 51.5 & 12 & 30 & 21 & 39,6 & 50 & 39.7 \\
$\quad \begin{array}{l}\text { Kurang Baik } \\
\text { Baik }\end{array}$ & 0 & 0 & 3 & 7,5 & 0 & 0 & 3 & 2,4 \\
\hline
\end{tabular}

Sumber : Data Primer, 2018

Tabel 3. Distribusi Frekuensi Tingkat POS berdasarkan Indikator Penghargaan Organisasi terhadap Kontribusi dan Perhatian Organisasi terhadap Kehidupan Pegawai di RSUD Kelas B

\begin{tabular}{|c|c|c|c|c|}
\hline \multirow{3}{*}{ Indikator Tingkat POS } & \multicolumn{4}{|c|}{ Tingkat POS } \\
\hline & \multicolumn{2}{|c|}{ Kurang Baik } & \multicolumn{2}{|c|}{ Baik } \\
\hline & $\mathbf{n}$ & $\%$ & $\mathbf{n}$ & $\%$ \\
\hline \multicolumn{5}{|c|}{$\begin{array}{l}\text { Indikator penghargaan organisasi terhadap kontribusi } \\
\text { pegawai }\end{array}$} \\
\hline Cara RS menghargai kontribusi & 54 & 42.9 & 72 & 57.1 \\
\hline Cara RS mengapresiasi usaha & 75 & 59.5 & 51 & 40.5 \\
\hline Respon RS terhadap keluhan & 32 & 25.4 & 94 & 74.6 \\
\hline Tanggapan RS terhadap performa & 79 & 62.7 & 47 & 37.3 \\
\hline \multicolumn{5}{|c|}{$\begin{array}{l}\text { Indikator perhatian organisasi terhadap kehidupan } \\
\text { pegawai }\end{array}$} \\
\hline Cara RS menanggapi keinginan & 11 & 8.7 & 115 & 91.3 \\
\hline Cara RS memperhatikan kepuasan kerja & 81 & 64.3 & 45 & 35.8 \\
\hline Bentuk perhatian RS terhadap pegawai & 84 & 66.7 & 42 & 33.3 \\
\hline Tanggapan RS saat menorehkan prestasi & 89 & 70.6 & 37 & 29.4 \\
\hline
\end{tabular}

Sumber : Data Primer, 2018

responden masih kurang baik, sedangkan persepsi responden tentang cara rumah sakit menghargai kontibusi $(57,1 \%)$ dan keluhan responden $(74,6 \%)$ sudah baik. Selanjutnya berdasarkan indikator perhatian organisasi terhadap kehidupan pegawai. $91,3 \%$ responden memiliki persepsi baik terkait cara rumah sakit menanggapi keinginan. Namun, persepsi terkait cara RS memperhatian kepuasan kerja $(64,3 \%)$, bentuk perhatian RS terhadap pegawai $(66,7 \%)$ dan tanggapan RS saat menorehkan prestasi $(70,6 \%)$ masih kurang baik.

Selanjutnya gambaran persepsi responden tentang penghargaan organisasi kepada pegawai lebih spesifik dijelaskan pada tabel 4. Sebagian besar $(45,2 \%)$ responden memiliki persepsi bahwa rumah sakit memberikan kesempatan untuk mengikuti pendidikan atau pelatihan. Namun, ditinjau dari cara rumah sakit mengapresiasi usaha, $51.6 \%$ responden memiliki persepsi bahwa tidak adanya perlakuan khusus dari rumah sakit. Adapun terkait respon rumah sakit terhadap keluhan, $67.5 \%$ responden memliki persepsi bahwa keluhan mereka ditanggapi secara wajar. Begitupun terkait tanggapan rumah sakit terhadap performa menunjukkan $38.1 \%$ responden memiliki persepsi rumah sakit menyadari performa mereka namun tidak ada tanggapan dari rumah sakit. Berdasarkan item pernyataan responden terkait perhatian organisasi $86,5 \%$ responden memiliki persepsi bahwa keinginan mereka dipertimbangkan oleh rumah sakit. Terkait kepuasan kerja, bentuk perhatian RS terhadap pegawai dan tanggapan saat 
Tabel 4. Distribusi Frekuensi Item Pernyataan Tingkat POS berdasarkan Indikator Penghargaan Organisasi terhadap Kontribusi dan Perhatian Organisasi terhadap Kehidupan Pegawai di RSUD Kelas B

Item Pernyataan Tingkat POS

Indikator Penghargaan Organisasi terhadap Kontribusi

Cara RS menghargai kontribusi

Tidak ada perlakuan khusus

Dipuji oleh atasan dan rekan kerja

Organisasi memberikan kesempatan untuk mengikuti pendidikan atau pelatihan

Organisasi memberikan reward berupa piagam penghargaan atau insentif

Cara RS mengapresiasi usaha

Tidak ada perlakuan khusus

Ada toleransi keterlambatan kerja

Rekan kerja membantu saya menyelesaikan pekerjaan

Ada tambahan remunerasi

Respon RS terhadap keluhan

Tidak ditanggapi

Kurang mendapat tanggapan

Langsung diterima

Ditanggapi secara wajar

Tanggapan RS terhadap performa

Organisasi jarang menyadari hal itu

Disadari tetapi tidak ada tanggapan

Diberikan pujian oleh atasan atau rekan kerja

Diberikan reward

Indikator Perhatian Organisasi terhadap Kehidupan Pegawai

Cara RS menanggapi keinginan pegawai

Tidak ditanggapi

Ditolak

Langsung diterima

Dipertimbangkan

Cara RS memperhatikan kepuasan kerja

Tidak ada program khusus terkait kepuasan pegawai

Organisasi selalu berupaya menyediakan lingkungan yang nyaman untuk bekerja

Beban kerja yang diberikan setara dengan insentif yang didapatkan

Memperhatikan kehidupan ekonomi pegawai

Indikator Perhatian Organisasi terhadap Kehidupan Pegawai

Bentuk perhatian RS terhadap pegawai

Tidak ada perhatian khusus

Perhatian hanya diberikan kepada orang-orang tertentu

Saya sering mendapat kejutan di hari ulang tahun saya

Organisasi mempu membaca dan memenuhi kebutuhan saya ditempat kerja

Tanggapan yang saya dapatkan saat menorehkan prestasi

Tidak ada perlakuan khusus

Saya mendapat fasilitas ekstra untuk menunjang pekerjaan saya

Organisasi memberikan insentif khusus atas apresiasi tersebut

Organisasi bangga memiliki saya sebagai pegawai dan saya menjadi salah satu orang

yang diperhitungkan dalam organisasi

n $\%$

48

38,1

$6 \quad 4,8$

$57 \quad 45,2$

$15 \quad 11,9$

$65 \quad 51,6$

$10 \quad 7,9$

$29 \quad 23,0$

$22 \quad 17,5$

$3 \quad 2,4$

$29 \quad 23,0$

$9 \quad 7,1$

$85 \quad 67,5$

$31 \quad 24,6$

$48 \quad 38,1$

$32 \quad 25,4$

$15 \quad 11,9$

Sumber : Data Primer, 2018 
Tabel 5. Hubungan antara Perceived Organizational Support dan Kinerja Dokter

\begin{tabular}{cccc}
\hline \multicolumn{1}{c}{ Variabel } & Nilai p & Nilai r \\
\hline $\begin{array}{c}\text { Perceived Organizational } \\
\text { Support }\end{array}$ & Kinerja Dokter & 0.010 & 0.229 \\
\hline
\end{tabular}

Sumber : Data Primer, 2018

menorehkan prestasi menunjukkan sebagian besar $(>50 \%)$ responden menyatakan tidak ada program khusus maupun perlakuan khusus pada responden. Selanjutnya untuk mengetahui hubungan tingkat POS terhadap kinerja dokter, dilakukan analisis bivariat. Tabel 5 menunjukkan adanya korelasi antara POS dengan kinerja dokter dengan nilai p-value $(0.010)<0.05$ dan besar korelasi 0.229 yang berada dalam kategori korelasi lemah.

\section{PEMBAHASAN}

Temuan pada penelitian ini menunjukkan POS memiliki hubungan dengan kinerja dokter, hasil penelitian ini sejalan penelitian yang dilakukan oleh Darolia, dkk dalam Kaur yang menyatakan bahwa POS memiliki hubungan terhadap kinerja pegawai. ${ }^{11}$ Penelitian yang juga dilakukan oleh Rhoades membahas berdasarkan meta analisis dari 70 studi menunjukkan bahwa POS dapat meningkatkan kinerja. Namun, dalam beberapa penelitian ditemukan juga bahwa POS tidak berpengaruh langsung dengan kinerja hanya sebagai variabel mediasi dari beberapa variabel perilaku organisasi. ${ }^{13,14}$

Hasil analisis menunjukkan nilai korelasi (r) antara POS dengan kinerja dokter adalah 0.226. Nilai korelasi (0.22-0.399) ini menunjukkan hubungan yang tidak cukup kuat atau rendah. ${ }^{15}$ Wenghover, dkk dalam Van den Goor menyatakan bahwa faktor individu dan faktor organisasi mempengaruhi kinerja dokter. Namun, faktor individu mempunyai signifikansi pengaruh lebih besar dibandingkan faktor organisasi terhadap kinerja dokter. Persepsi dokter terkait POS hanya salah satu komponen dalam faktor individu yang mempengaruhi kinerja dokter, sehingga terdapat komponen di luar persepsi individu yang juga berkontribusi mempengaruhi kinerja. ${ }^{16}$ Robbins dan Judge ${ }^{17}$ dalam teori perilaku organisasi menggambarkan selain persepsi, faktor individu meliputi ciri biografis, kepribadian, nilai dan sikap, motivasi serta pembelajaran individu. Keseluruhan kom- ponen individu ini mempengaruhi pengambilan keputusan individu yang juga berpengaruh pada persepsi individu pada tingkat unit dan organisasi.

Hasil penelitian ini, penghargaan rumah sakit terhadap kontribusi dokter yang dipersepsikan baik hanya tentang cara rumah sakit menanggapi keluhan. Namun, untuk mengapresiasi kontribusi atau performa masih belum baik. Hal ini mengindikasikan belum adanya sistem reward terkait penghargaan atas kontribusi dokter. Sistem reward yang diterapkan di rumah sakit lebih berfokus pada kesempatan untuk mendapatkan pendidikan dan pelatihan (45.2\%) dan adanya remunerasi (17.5\%) (Tabel 4). Selanjutnya terkait perhatian rumah sakit terhadap dokter, dokter memiliki persepsi yang baik hanya pada cara rumah sakit menanggapi keinginan dokter. Namun, dalam menanggapi rumah sakit hanya dalam sebatas mempertimbangkan keinginan dokter, belum ada program khusus untuk memperlihatkan perhatian rumah sakit terhadap dokter. Gambaran kedua indikator ini yang kemudian dipersepsikan oleh responden bahwa tidak adanya dukungan dari organisasi terhadap dokter.

Persepsi POS yang baik merupakan salah satu bentuk keberhasilan organisasi karena menggambarkan pegawai memiliki kepercayaan terhadap organisasi. Pengukuran tingkat POS mempunyai pengaruh yang baik untuk organisasi maupun kesehatan mental pegawai dalam bekerja. ${ }^{13}$ Rhoades menjelaskan bahwa ketika pegawai percaya terhadap organisasi, mereka akan memiliki sense of obligation (rasa kewajiban) dan akan bekerja lebih keras secara sukarela. ${ }^{13}$ Proses selanjutnya pegawai akan merasa bahwa organisasi adalah sumber kepuasan sosial dan emosional, menjadi tempat mereka mendedikasikan diri dengan perasaan dihargai dan diperhatikan. Akhirnya keyakinan bahwa mereka dihargai secara adil dalam organisasi memotivasi mereka untuk bekerja dengan baik dan terlibat bahkan tanpa imbalan nyata.

Menurut Rhoades bentuk umum yang dapat dirasakan oleh pegawai terkait adanya duku- 
ngan organisasi meliputi: pertama terkait keadilan struktural dan prosedural yang menyangkut cara yang digunakan untuk menentukan pendistribusian sumber daya manusia diantara pegawai, keadilan yang berkaitan dengan aturan-aturan formal dan kebijakan bagi pegawai serta keadilan dalam penerimaan informasi yang akurat. Keadilan sosial dapat disebut juga keadilan interaksional, hal ini berkaitan dengan cara organisasi memperlakukan pegawai dengan hormat dan bermartabat. Kedua terkait dukungan manajer yang menggambarkan sejauh mana manajer memiliki perhatian terhadap pegawai dan peduli terhadap kesejahteraan pegawai. Dukungan manajer memiliki kaitan erat dengan persepsi pegawai terhadap dukungan organisasi, karena pegawai sebagai agen organisasi yang memiliki tanggung jawab untuk mengarahkan, mengkomunikasikan kebijakan dan mengevaluasi kinerja bawahan. Ketiga terkait penghargaan dari organisasi dapat meliputi gaji, tunjangan, bonus, promosi, pelatihan/pengembangan diri serta kondisi kerja yang nyaman dan aman bagi pegawai. ${ }^{13}$

Implementasi dukungan organisasi dalam industri perumahsakitan khususnya menggambarkan hubungan rumah sakit dengan dokter, Amer Kaissi 18 menyebut konsep ini dengan "Physician Engagement" (Keterlibatan Dokter) yang didefinisikan sebagai kontribusi aktif dan positif dokter dalam menjalankan peran dan meningkatkan kinerja, yang dengan sendirinya dokter mengakui berkomitmen untuk mendukung pelayanan yang berkualitas. Gambaran proses physician engagement memiliki kesamaan dengan proses POS yang digambarkan Rhoades $^{9}$ dalam hal ini keterlibatan dokter tidak dilihat dari perspektif dokter saja, namun organisasi perlu menyiapkan sistem untuk menempatkan pada proses dan kondisi apa dokter berpartisipasi dalam organisasi. ${ }^{20}$ Trybou, dkk melakukan penelitian terkait hubungan rumah sakit dengan dokter di rumah sakit Belgia ditemukan bahwa faktor dukungan organisasi, pimpinan, kesempatan belajar dan upah mempengaruhi hubungan organisasi terhadap dokter. ${ }^{21}$ Penelitian ini menggambarkan bahwa konsep POS pada pimpinan atau manajer dan dokter perlu menjadi salah satu prioritas rumah sakit dikarenakan perbedaan cara pandang, nilai, ekspektasi serta pendekatan manajer rumah sakit dan dokter dalam pengelolaan rumah sakit. ${ }^{18}$

Beberapa rumah sakit di Kanada, Inggris, dan Amerika Serikat telah mengimplementasikan konsep Physician Engagement sebagai bentuk fokus hubungan rumah sakit terhadap dokter. Penerapan program terkait keterlibatan dokter baik secara individu, tingkat departemen, maupun organisasi disusun secara detail sehingga dokter memiliki persepsi pentingnya peran dokter dalam konteks manajemen. ${ }^{22}$ Bentuk POS ini lebih kepada bentuk keadilan prosedural. Tentunya proses ini membutuhkan kerjasama manajer untuk memahami dan menghormati perbedaan mereka dengan dokter, menyetujui dan tidak menyetujui aturan yang didasarkan integritas, pemenuhan janji, menghindari serangan pribadi, berusaha untuk menemukan pendekatan bersama dengan dokter untuk mengelola sumber daya. ${ }^{22}$

Malik, dkk melakukan penelitian tingkat POS pada 160 dokter di rumah sakit swasta dan pemerintah merekomendasikan bahwa organisasi perlu meninjau sistem manajemen agar menjadi lebih partisipatif sehigga menciptakan lingkungan kerja yang positif. ${ }^{23}$ Dale menjelaskan lebih spesifik hubungan rumah sakit dengan dokter dapat dibangun dengan menyepakati nilai yang kemudian ditulis dalam aturan mencakup harapan rumah sakit terhadap perilaku dokter dan sebaliknya harapan dokter terkait keterlibatannya di rumah sakit. ${ }^{24}$ Sebagai contoh dokter berkomitmen untuk aktif terlibat dalam peningkatan kualitas dan rumah sakit berkomitmen untuk melibatkan dokter dalam pengambilan keputusan strategik, transparansi keuangan rumah sakit, memastikan rumah sakit dikelola dengan baik serta rumah sakit menunjukkan penghargaan terhadap dokter.

Penelitian ini masih perlu dilakukan penelitian lanjutan dikarenakan teori Aisenberger dan Huntington yang digunakan pada instrumen penelitian ini masih sangat umum sehingga diperlukan pengembangan instrumen POS pada tenaga dokter di rumah sakit yang menyesuaikan dengan kondisi organisasi di rumah sakit.

\section{KESIMPULAN DAN SARAN}

Hasil penelitian menunjukkan adanya hubungan antara Perceived Organizational Support dengan kinerja dokter. Rumah sakit perlu menciptakan lingkungan kerja yang supportif dan 
membuat program inovasi yang berfokus pada dukungan organisasi terhadap dokter agar meningkatkan rasa kepercayaan dokter terhadap rumah sakit.

\section{DAFTAR PUSTAKA}

1. Undang-Undang RI Nomor 44 Tahun 2009 tentang Rumah Sakit. Jakarta: Republik Indonesia; 2009.

2. Sathiadas G. Challenges and Strategies in Implementing Workplace-Based Assessments in the Sri Lankan Medical Education System. Journal of the Postgraduate Institute of Medicine. 2018:5(2);1-9.

3. Shiba K, Nishimoto M, Sugimoto M, dan Ishikawa Y. The Association between Meditation Practice and Job Performance: A Cross-Sectional Study. Plos One. 2015:10(5);1-13.

4. KARS. Standar Nasional Akreditasi Rumah Sakit (SNARS) edisi 1. Jakarta: Komisi Akreditasi Rumah Sakit; 2017.

5. Kementrian Kesehatan RI. Pedoman Penyusunan Standar Pelayanan Minimum di Rumah Sakit. Jakarta: Kementrian Kesehatan RI; 2013.

6. Unit Rekam Medik RSUD Labuang Baji Makassar. Profil Rumah Sakit Umum Daerah Labuang Baji Makassar Tahun 2017. Makassar: RS Labuang Baji; 2017.

7. Unit Perencanaan RSUD Haji Makassar. Profil Rumah Sakit Umum Daerah Haji Makassar Tahun 2017. Makassar: RSUD Haji; 2017.

8. Unit Rekam Medik RSUD Kota Makassar. Profil Rumah Sakit Umum Daerah Kota Makassar Tahun 2017. Makassar: RSUD Kota Makassar; 2017.

9. Kopelman R. Managing Productivity in Organization a Practice People Oriented Prespective. New York: McGraw Hill Book Company; 1988.

10. Riggle, R. J., Edmondson, D. R., dan Hansen JD. A Meta-Analysis of the Relationship between Perceived Organizational Support and Job Outcomes: 20 Years of Research. Jornal of Business Research. 2009:62(10);10271030.

11. Kaur S, Aneet. Perceived Organizational Support and Affective Commitment: A Demographic Analysis. Journal of Business
Management. 2017:19(1);54-59.

12. Yongxing, G., Hongfei, D., Baoguo, X., dan Lei M. Work Engagement and Job Performance: the Moderating Role of Perceived Organizational Support. Anales Psicologia. 2017:33(3);708-713.

13. Rhoades L dan Eisenberger R. Perceived Organizational Support: A Review of The Literature. Journal of Applied Psychology. 2002:87(4);698-714.

14. Erdem Haluk, Turen Ufuk, Gokmen Yunus, dan Tuz Oguz. Perceived Organizational Support, Stress Coping Behaviors and Mediating Role of Psychological Capital: Special Education and Rehabilitation Centers. Scientific Annals of Economics and Business. 2017:64(3);359-377.

15. Sugiyono. Metodologi Penelitian. Jakarta: PT. Gramedia; 2007.

16. Van den Goor, M. M. P. G., Wagner, C. C., \& Lombarts KMJMH. Poor Physician Performance in the Netherlands: Characteristics, Causes, and Prevalence. Journal of Patient Safety. 2015. Available at: http://www.ncbi. nlm.nih.gov/pubmed/?term=26176988

17. Robbins, S. P., \& Judge TA. Organizational Behavior. (S. Yagan, Ed.) Vol. 91, Pearson Education. United State of America: Pearson; 2017.

18. Kaissi A. Manager-Physician Relationships: An Organizational Theory Perspective. The Health Care Manager. 2005:24(2);165-176.

19. Rhoades L ER. Perceived Organizational Support: A Review of The Literature. Journal of Applied Psychology. 2002;87(4):698-714.

20. Farahani MJ, Fereydoni M. Providing a Model for the Effect of Organizational Spirituality and Ethics on Job Involvement in Experts of the Ministry of Sport and Youth. Journal Sport Management. 2017:9(2);273286.

21. Trybou, J., Gemmel, P., Vaerenbergh, YV., dan Annemans L. Hospital-Physician Relations: The Relative Importance of Economic, Relational and Professional Attributes to Organizational Attractiveness. BMC Health Service Research. 2014:14(232);1-9.

22. A TAP, Perrier L, Prokopy M, Neves-Mera L, D David Persaud. Physician Engagement: 
A Concept Analysis. Journal of Healthcare Leadership. 2019:11;101-113.

23. Malik SZ, Kazmi SZ, Nadeem N. The Effect of Perceived Organizational Support on Doctor's Organizational Commitment in Pakistan.
The Lahore Journal Business. 2016:4(2);7392.

24. Dale McMurchy. Evidence Synthesis: Strategies and Approaches to Enhance Family Physician Engagement. 2018:1;1-22. 